$\operatorname{DOE} / m c / 21181-T_{5}^{21181.626} 4$ EOEXPLORERS INTERNATIONAL, INC.

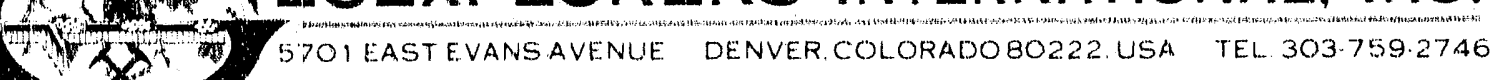

DR. JAN KRASON

$\mathrm{DOE} / \mathrm{MC} / 21.181--\mathrm{T} 5$

PRESIOENT

DE92 017659

SECOND ANNUAL TECHNICAL PROGRESS REPORT ON

TEVALUATION OF THE GEOLOGICAL RELATIONSHIPS TO GAS HYDRATE, FORMATION AND STABILITY"

\author{
Period: October 1, 1985 through September 30, 1986 \\ Reference: U.S. Depariment of Energy (DOE) \\ Morgantown Energy Technology Center (METC) \\ Contract NO. DE-AC21-84MC21181
}

\title{
PERSONNEL.
}
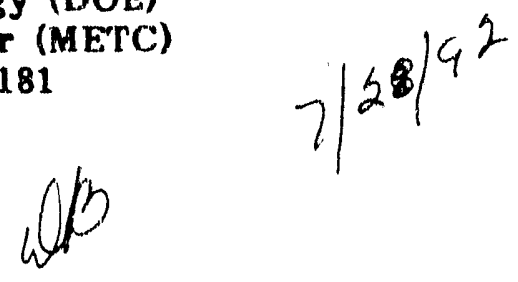

During the reporting period, the following staff personnel were involved in the contract's executior: Dr. Jan Krason (Principal Investigator); Mr. Marek Ciesnik (Geologisti; Mr. Patrick Finley (Geochemist - Geologist); and Ms. Margalet Krason (Technical Assistant - Graphic Artist).

\section{WORK ACTIVITTES}

The reporting period covers the second year of Geoexplorers' International, Inc. contract with the U.S. DOE-METC. The scope of the project has not been changed and the format of presentation of the study results has generally been the same as the one already established during the first year of our contractual work. However, the budget initially foreseen for the second year of our work has been split into two years (see Contract's Amendment No. MO05, June 18, 1986).

Also during the second year of our contractual work for DOE-METC we have experienced that although there are many publications pertaining to gas hydrates, their formation and stability in various geological conditions are poorly known. Therefore, for the same reasons and because of the very broad scope of our research, limited amount and extremely dispersed information, the study regions are very large. Moreover, almost without exception the geological environments controlling gas hydrates formation and stability of the studied regions are very complex. Consequently, the progress of our work in terms of the number of locations with gas hydrates designated for study by DOE-METC (ir: 24 offshore locations) is previously foreseen. The regions studied (completed and partially completed - total 17 locations) during the reporting period, particularly the Gulf of Mexico and the Middle America Trench, are the most important in this entire research project. In the past, both of these regions have been extensively studied,

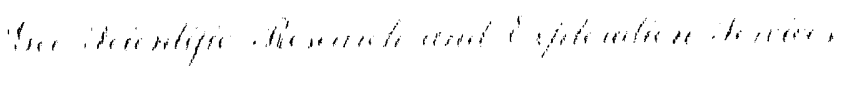




\section{DISCLAIMER}

This teport was prepareat as an account of work sporisored by an agericy of the United States Government. Neither the United States Government nor any agency thereof, nor any of their employees, makes any warranty, express or implied, or assumes any legal liability or responsibility for the accuracy, completeness, or uscfulness of any information, apparatus, product, or process disclosed, or represents that its use would not infringe privately owned rights. Refer. ence herein to any specific cornmercial product, process, or service by trade name, trademark, manufacturer, or otherwise does not necessarily constitute or imply its endorsement, recom. mendation, or favoring by the United States Government or any agency thereof. The views and opirions of authors expressed herein do not necessarily state or reflect those of the United States Government or any agency therenf. 
the gas hydrates were confirmed and recovered. In our investigation it was necessary not only to review all previous data and interpretations, but to do a thorough analysis of the basins, and a critical evaluation of all previously reported and publicly available but not published information. If one realizes that many scientists have dedicated their entire careers to the study of the geology of either the Gulf of Mexico or the Middle America Trench our accomplishments, in a relatively very short time, pertaining to either and both of these regions, are at least considerable.

During the same second year of Geoexplorers' International contract work for DOE-METC we have also completed the basin analysis, determined formation and stability of gas hydrates in the Colombia Basin, Panama Basin, offshore Northern California, and considerably advanced studies of the Aleutian Trench and the Bering Sea regions (nb. both are extremely big and discussed in hundreds of published an unpublished papers, reports, maps, and many others).

At the same reporting period we have prepared a special summary of completed work and a poster presentation which were included in the program of "Gas Hydrates, Arctic/Offshore Research, and Deep Source Gas Concentrates Review Meeting" held in Morgantown, West Virginia on March 25-26, 1986. Both our presentations have been published by the U.S. Department of Energy and are included in the "Proceedings of the same meeting", edited by C.A. Komar (March, 1986).

A similar topic to the one presented at the meeting in Morgantown, West Virginia, but entitled "Gas Hydrates in the Continental Margins", we also discussed (in May, 1986) with Professors E. Dendy Sloan and M.S. Selim and the students of the Chemical Eng. and Petrol. Refining Department, Colorado School of Mines. We consider this a form of cooperation with another contractor of the DOE-METC.

The results of Geoexplorers' International study are reported concurrently with the work and included in our very detailed "Monthly Progress Reports". During the reporting period 12 such reports (4 copies of each) have been submitted to DOE-METC. We wish to emphasize that some of our Monthly Progress Reports can be considered for publication as independent papers. Overall, they are subsequently incorporated as chapters of much larger reports separately covering each of the studied regions.

Therefore, the following are only highlights on the regions studied either completed or still under investigation and the reports are being prepared:

\section{Colombia Basin}

Our initial investigation of the data pertaining to the Colombia Basin was started in September, 1985. Subsequently, the main part of the literature and unpublished data investigation, its study and critical evaluation has been completed in March, 1986. At the same time, a draft of our report has been prepared and submitted to DOE-METC (March 25, 1986).

Although initially we intended to make a quick study and a very short report, our research proved that the Colombia Basin study region, which covers approximately $400,000 \mathrm{~km}^{2}$, has one of the highest probabilities for widespread gas hydrates. In numerous locations of this Basin the bottom simulating reflectors (BSRs) are unusually distinct. In the course of our study we have greatly enlarged the number of seismic profiles showing BSRs. 
In the Colombia Basin the BSRs occur in a thick, undeformed sediments of abyssal zone. Seismic lines indicate the presence of gas hydrates in the region. The BSRs are very widespread over the continental margin beneath water depths of $900-4,000 \mathrm{~m}$.

A synthesis of relevant geological factors indicates that the marginal deformed belts and the abyssal plain sediments have the greatest potential for a large volume of gas trapped in the form of hydrates.

Sampling the subbottom sediments and deep drilling could verify our interpretations. Reprocessing seismic data and collecting more seismic information would permit more precise assessment of potential gas resources trapped in and beneath gas hydrate-bearing zones. At this time an estimated/inferred gas volume, at $25^{\circ} \mathrm{C} / \mathrm{atm}$., amounts to $12.5 \mathrm{TCF}$ in the Colombia Basin itself, and 13 TCF in the Marginal Deformed Belts.

The final copies of the "Colombia Basin Report" have been mailed to DOE-METC on June $16,1986$.

\section{Panama Basin}

In November, 1985 we began search for litel:ature and seismic data pertaining to the offshore of Pacific coasts of Panama and Colombia. Subsequently, we have referred to this study region as the "Panama Basin". Our study region included $1,200,000 \mathrm{~km}^{2}$. The Panama Basin includes portions of the Nazca, Cocos, and South America tectonic plates. To the north the Panama Basin borders with the Caribbean plate. The submarine topography, faulting systems, sedimentation processes, and many other development features of the Panama Basin are largely determined by the complex interplay of the above mentioned major tectonic plates. Although the results of the Deep Sea Drilling Project's (DSDP) data greatly contributed to the geologic knowledge of the region, the amount of information directly relevant to this project objectives is still very limited. Nevertheless, thorough analysis and critical evaluation of available data enabled us to conclude the following (for details see Monthly Progress Reports October 21, 1986 through March 20, 1986, and the final report mailed to DOE-METC on June 16, 1986):

1. The Panama Basin is naturally bounded. To the south it is limited by the Galapagos Islands which in the suboceanic surface is extended into the Carnegie Ridge; the Cocos Ridge forms the western and northwestern boundary, then Panama, Colombia, and Ecuador limit the Panama Basin to the north and east.

2. The depth of the basin ranges from some ten meters at the continental shelf and around the islands, up to $3,600 \mathrm{~m}$ below sea level in the central parts of the basin.

3. The structural development of the Panama Basin resulted from a complex interplay of four major tectonic plates: Nazca, Cocos, South American, and Caribbean. Thus, the internal structure of the Panama Basin is very complex. Besides the prevailing ridge type structures, there are also systems of grabens and troughs.

4. Seismic data reveals horizontal stratification of sediments unevenly covering the ridges. 
5. The sedimentary pattern in the Panama Basin is defined by its tectonic history and high biogenic production. The central part of the Galapagos Rifting Zone and highly elevated ridges and other tectonic blocks are free of sediments. The thickest sedimentary sequence (up to $1,500 \mathrm{~m}$ ) occurs in the marginal troughs of the basin.

6. The available data are insufficient for detailed lithostratigraphic correlation of the sedimentary sequence in the Panama Basin. Nevertheless, lithological features have been used for lithostratigraphic subdivision of the sedimentary sequence of each individual DSDP site.

7. Thorough analysis of seismic data, the bottom simulating reflectors originally reported from Panama Basin by Shipley et al. (1979) have been confirmed and one new location with BSRs, along Panama, the Colombia and Ecuador continental margins was found.

8. It is concluded that the most favorable conditions for gas hydrates occur in areas of relatively flat continental slopes and upper rises where the oceanic water depth does not exceed $2,000 \mathrm{~m}$.

9. In the vertical section, the top of the sedimentary sequence in the continental margins of the Panama Basin appears to be very favorable for the disseminated type of gas hydrates. Yet, much better conditions for gas hydrate formation and stability exist in the sediments of high permeability.

10. Because of insufficient data, the assessment of gas resource potential in the Panama Basin is being made only hypothetically. Nevertheless, we are quite confident that the thickness of the gas hydrate stability zone varies from 200 to $336 \mathrm{~m}$ (based on the presence of BSRs and thermal-pressure conditions). The maximum ocean depth at the locations with BSRs is approximately $2,600 \mathrm{~m}$.

11. Thus, estimated resources of hydrocarbon gas accumulated in the hypothetical hydrate zone of the continental margin within the Panama Basin, amounts to 6.8 TCF per $1 \mathrm{~m}$ of thickness of sediment saturated with gas hydrates. In a possible $300 \mathrm{~m}$ thickness of gas hydrate-bearing zone, potential gas resources are estimated at 2,040 TCF.

\section{Northern California Offshore}

Our basin analysis and gas hydrates in the northern California offshore study region was started at the end of March, 1.986 and the draft report was mailed to DOE-METC in June, 1986. After review and suggested improvements, and then after Geoexplorers' additions and alterations, the final report was mailed back to DOE-METC on October $30,1986$. 
The geology of this study region is also complex, and moreover, most of the new data is still being withheld as propriatory either by the U.S. Geological Survey (USGS) and/or by various companies. Thus, the access to unpublished data (including that which is of ficially in the public dornain) was our main difficulty, especially when studying the northern California offshore region.

Nevertheless, identification of the gas hydrates in the northern Califurnia offshore is based almost exclusively on seismic survey data. These data revealed widespread BSRs, which are considered as primary indicators of the presence of gas hydrates. The BSRs cover at least $3,000 \mathrm{~km}$ and are widespread in the continental margin of California, north of Cape Mendocino. Temperature and pressure conditions in the areas of BSR occurrences are conformable with the gas hydrate stability field, which in the northern California offshore should be within approximately $200 \mathrm{~m}$ of the subbottom sedimentary sequence.

Analysis of available geological and geophysical data allowed us to conclude as follows (see details in the Monthly Progress Reports and Final Report):

1. Northern and central parts of the study region are underlain by metasedimentary rocks while in the southern part occurs a granitic basement. The type of basin's basement is often reflected in the deformation of the overlying sedimentary sequence.

2. The lithostratigraphic profiles in the entire area show a prevailing shallow marine type of sediments.

3. Analyses of gas extracted from the near seafloor sediments in Eel River Basin seems to indicate the thermogenic origin of gas.

4. Lack of suitable geochemical data has not permitted unequivocal establishment of the hydrocarbon source rocks, their distribution, and hydrocarbon generation potential.

5. The migration of thermogenic hydrocarbons is mainly controlled by fault systems.

6. No significant hydrocarbon accumulations have been found in onshore extensions of the offshore Eel River and Point Arena basins.

7. The geothermal gradient in the northernmost continental margin is calculated from gas hydrate stability conditions to be approximately $5.5^{\circ} \mathrm{C} / 100 \mathrm{~m}$.

8. Thermal regimes and hydrocarbon generation potential seem to constitute major conditions defining the potential for gas hydrates in the northern California of fshore.

9. Estimated gas potential reserves in the gas hydrate zone in northern California offshore amount to 84.8 TCF. 


\section{Middle America Trench}

Research on the Middle America Trench was begun in early March, 1986 with an initial search of seismic material from the area. Work on the Middle America Trench was suspended until mid April to prepare material for the annual contractors review and for vacation by $\mathrm{Mr}$. P. Finley. Work continued through the end of the fiscal year.

Initial literature review was time consuming due to the voluminous nature of the published literature on the study region. The large number of DSDP holes drilled (21) resulted in over 4,000 pages of potentially relevant work to be carefully evaluated. Concepts pertaining to the geological evolution of the region have only recently been clarified, which necessitated an extremely thorough compilation of very recent work to insure the accuracy of the report.

The concurrent review of unpublished seismic records from the study involved both verifying published reports of gas hydrate presence and searching for unreported evidence of gas hydrates. The search was fruitful; abundant seismic evidence of gas hydrates throughout a large area in the northern part of the study region was discovered. Additionally, we were able to verify that a seismic reflector which had been identified in a published report as a gas hydrate reflector was in fact a sediment reflector.

The importance of the Middle America Trench DSDP cores to both the geological community and to gas hydrate researchers has led to many independent studies of individual properties of the sediments. Until our study was begun these studies had not been systematically reviewed to determine possible overlap or contradictions among them. The tremendous volume of geochemical data resulting from these investigations permitted the use of computerized data base management techniques to ascertain the reliability and significance in the observations. In many cases, our use of all available data in an accessible form allowed us to use the results of seemingly unrelated studies to further the understanding of gas hydrate stability and formation in geological environments.

In addition to the raw data, previous investigators had presented many interpretations of the geology and gas hydrate occurrences of the regions. Our geochemical data base and our familiarity with the subject acquired during this project were brought to bear on the conflicting views.

The conflicting issues addressed in our study have major resource implications. As reported in the literature, the change in pore water chemistry due to gas hydrate formation could be extended for use in volumetric estimates of in place gas hydrate resources. The abundant geologic and geochemicai data from the study region suggest that this parameter cannot be directly applied to resource estimates. Two prevailing theories of massive gas hydrate formation have been proposed in the literature based on drilling in the study region. Our analysis shows that the more widely accepted theory is at odds with the geologic and geochemical data. A lesser known theory fits the existing data very well. A more accurate theory can be extended to suggest that massive gas hydrates may be more common occurrences, and that exploration for such resources can progress using extensive technology.

The Middle America Trench is the premier location for gas hydrates in the world. The abundance of direct and indirect observations in the region provides basic data which can be directly applied to regions in which the gas hydrate distribution is not as well known. 
Our study on the gas hydrates of the region makes the results of many researchers available to the scientific community in the form of a concise interpretative review of all relevant material.

\section{Aleutian Trench and Bering Sea}

Our studies on the gas hydrate potential in the Aleutian Trench and Bering Sea regions were initiated in July, 1986.

The two regions encompass huge territories of the northern Pacific and Bering Sea shelves (the Aleutian Trench is gver $3,000 \mathrm{~km}$ long and the shelf part of the Bering Sea covers $1,900,000 \mathrm{~km}^{2}$ ).

As both regions have closely related evolution, we decided to present them in one report. The joint consideration of the two regions provides useful background in understanding of the geological developments on the basins. The advantage of such an approach was saving more time for in depth basin analysis and studies of gas hydrates potential.

Tectonic evolution of the Aleutian Trench - Arc system and Bering Sea still remains in the center of dispute by many geologists. Therefore, thorough review of various hypotheses pertaining to tectonics required special efforts in order to reconcile the plate tectonics theories. Four areas were designated (by DOE-METC) for detailed studies. Two areas are located within the Aleutian Trench - Arc system and the other two within the Bering Sea shelf. From these four areas Kvenvolden and Bernard (1983) previously reported gas hydrates occurrences.

Only one of the two locations, in the Aleutian Trench, with suggested presence of gas hydrates, were sufficiently defined. In this case we could limit our study to a well delineated area. The second reported location with suggested gas hydrates presence was described as the "North Pacific Ocean, south of Aleutian Islands" (Kvenvolden and Bernard, 1983). In this case we were compelled to make a arbitrary choice and elected the eastern section of the Aleutian Trench - Arc system for our study. Such a choice was mainly dictated by the availability of drilling and analytical data from DSDP sites of Leg 19. Final reports from these sites provide direct geological and geochemical data across the trench and accretionary wedge south of the eastern Alaska Peninsula.

Our efforts to identify the geological factors controlling gas hydrate formation in the Bering Sea Shelf were concentrated on two major sedimentary basins: Navarin and Norton basins. These two major sedimentary basins are continuously of strong interest to government agencies and oil and gas industry. Therefore, despite the fact that 15 exploratory wells have been drilled in the Navarin and Norton basins (Steenblock, 1986) most of the data have not been publicly released. The most direct information in public domain relevant to the geological evolution, hydrocarbons related geochemistry of sediments and pore fluids, and geothermal regimes, are those included in the Navarin Basin COST Well No. 1 and Norton Basin COST Well No. 2. The latter data are extremely useful in the assessment of hydrocarbons potential in the Navarin and Norton basins, which is one of the most important factors in the processes of gas hydrate formation.

By the end of September, 1986 we completed writing the chapter on region tectonics of the Bering Sea and Aleutian Trench. The structural part of basin analysis of the Navarin Basin, Norton Basin, and central and eastern Aleutian Trench was completed. 


\section{Camera-Ready Final Reports and Published Reports}

Similarly as in the first year, during the second year of Geoexplorers' International contractual work for DOE-METC, we have made special efforts to prepare exceptionally high quality final reports. The camera-ready reports also make us responsible for the report content and its proper editorial format, illustrations, proof readings, etc. In all these extremely timeconsuming activities the DOE-METC reviewers of our reports, particularly Ms. Kathryn Dominic, Contracting Officer's Technical Fiepresentative, is very helpful and highly appreciaied.

All our reports are continuously, extensively illustrated, although illustrations are invaluable for high standard - quality reports, the preparation anc drafting of good illustrations also consumes a lot of time.

Since we feel responsible and proud of our work, we are exceptionally grateful to DOE-METC for the publication of all our final reports, including five volumes already published and three now in press. However, we also wish to share our concern that the printed version of our reports is not comparable with the quality of the camera-ready originals which we have submitted for publication. We are especially unhappy that the DOE printers do not realize the importance of proper margins (e.g. see in all reports excessive left and insufficient right margins on even numbered pages), pagination (e.g. all pages which start with a chapter's title should be numbered below the page's text, not at the top), clarity of illustrations, and others (e.g. totally different printing characters - from the text on those few pages which were retyped by DOE editors). In our opinion the layout of the title page is graphically much nicer than the layout of the covering page.

Thus, since we are confident that the U.S. DOE-METC would also prefer having and publishing outstanding reports not only with regard to their contents but as prestigious looking books, Geoexplorers International is suggesting and of fers much closer cooperation with DOE editors and printers.

We also wish to emphasize that in our opinion there will be a great demand for all "gas hydrates reports". Therefore, we also have compiled and provided DOE-METC a very extensive mailing list, including about 3,000 addresses of potential report buyers.

\section{GENERAI. COMMENTS}

Among the comments included in Geoexplorers' International previous Annual Report (i.e. October 1, 1984 through September 30, 1985) and which are also applicable for this reporting period we wish to emphasize the importance of our "Monthly Progress Reports". Every month we report factual work progress, providing DOE-METC in advance with information that is subsequently included in the reports on each separate region. We always appreciate and respect all comments and advice by Ms. Kathryn Dominic, Contacting Officer's Technical Representative.

We often face difficulties in our contractual work. The biggest problem is the access to propriatory information, particularly to drilling results and geophysical survey data. In this case, we use personal contacts, which in some cases are very helpful. We also have difficulties with access to the seismic survey data, including that which are officially in the public domain but still held by the U.S. Geological Survey. In some cases the seismic data is available but cannot be reproduced, instead, it can only be 
examined and then only in the USGS Office, in Menlo Park, California. Otherwise, accessibility to and cooperation with the USGS Library, other libraries, the National Oceanographic Data Center, NOAA, U.S. Department of Commerce, is exceptionally good.

We also wish to emphasize that since the project's financing foreseen for the second year of Geoexplorers' International contract with DOE-METC has been split into two years, since July, 1986 we have been using Geoexplorers' own financing. Thus, we have not stopped working on the DOE-METC project although we have considerably lowered the project's charges, and are very short with funds. Therefore, if additional financing from DOE-METC will not be available the remaining regions shall be examined very briefly and the "site reports" will have to be very limited in their content.

\section{THE WORK PLAN}

Aithough in Geoexplorers' International studies we cover much larger regions, analysing and evaluating much more material and preparing more extensive reports than originally anticipated, we are only slightly behind in the schedule that we have foreseen in our previous Annual Report and shown in Table 1 enclosed with Geoexplorers' presentation published in the "Proceedings of the Gas Hydrate, Arctic/Offshore Research, and Deep Source Gas Contraactors Review Meeting" (Komar, 1986). Thus, in spite of all the above mentioned factors, in our estimation, we have advanced the contractual work up to approximately $70 \%$ (i.e. status at the end of September, 1986). We have already expanded $82 \%$ of the original total contractual sum. All details pertaining to the financial status of DOE-METC Geoexplorers' International Contract are included in DOE Forms CR-535 and CR-533P (both are enclosed with our monthly invoices and the financial reports) and the up-dated work plan should be as follows (see also herewith enclosed Table 1 - Work Schedule - Milestones):

\section{Name of Gas Hydrate Site(s)} Vol.

1. Blake-Bahama Outer Ridge, West Atlantic Ocean

2. Baltimore Canyon Trough and Environs

3. Offshore Newfoundland and Labrador

4. Western Gulf of Mexico
DOE-METC'S Site Number

1

17,18
Tentative Date of Report's Delivery

Final report completed and published

Final report completed and published

Final report completed and published

Final report completed and published 
5. Gas Hydrates in Russian Literature

6. Panama Basin

7. Colombia Basin

8. Offshore of Northern California 9

9. Middle America Trench

$10-14$

$5-8$

Bering Sea Regions

11. Beaufort Sea, Offshore of Alaska, 4 Arctic Ocean

12. Black Sea, Offshore of Soviet Union

13. Timor Trough, Offshore of Northern Australia

14. Offshore of Angola, Eastern Atlantic Ocean

15. Gulf of Oman, Northwestern Indian Ocean

16. Nankai Trough, Offshore of Japan 19

17. Offshore of New Zealand
Final report completed and published

Final report completed and in press

Final report completed and in press

Final report completed and in press

November 15, 1986

November 30,1986

January 15,1987

January 31,1987

February 28, 1987

April 3C, 1987

June 31,1987

April 30,1987

June 30,1987 


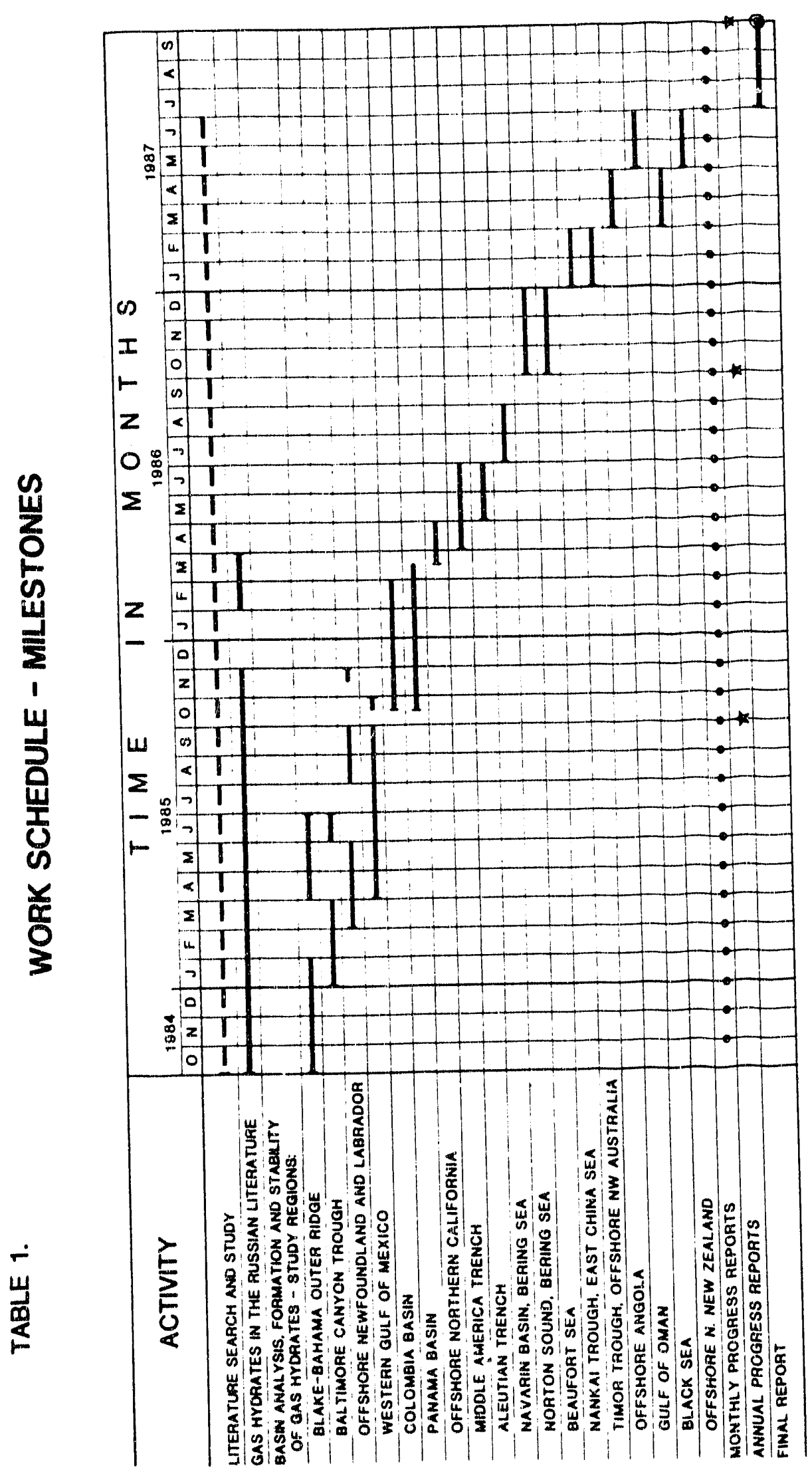



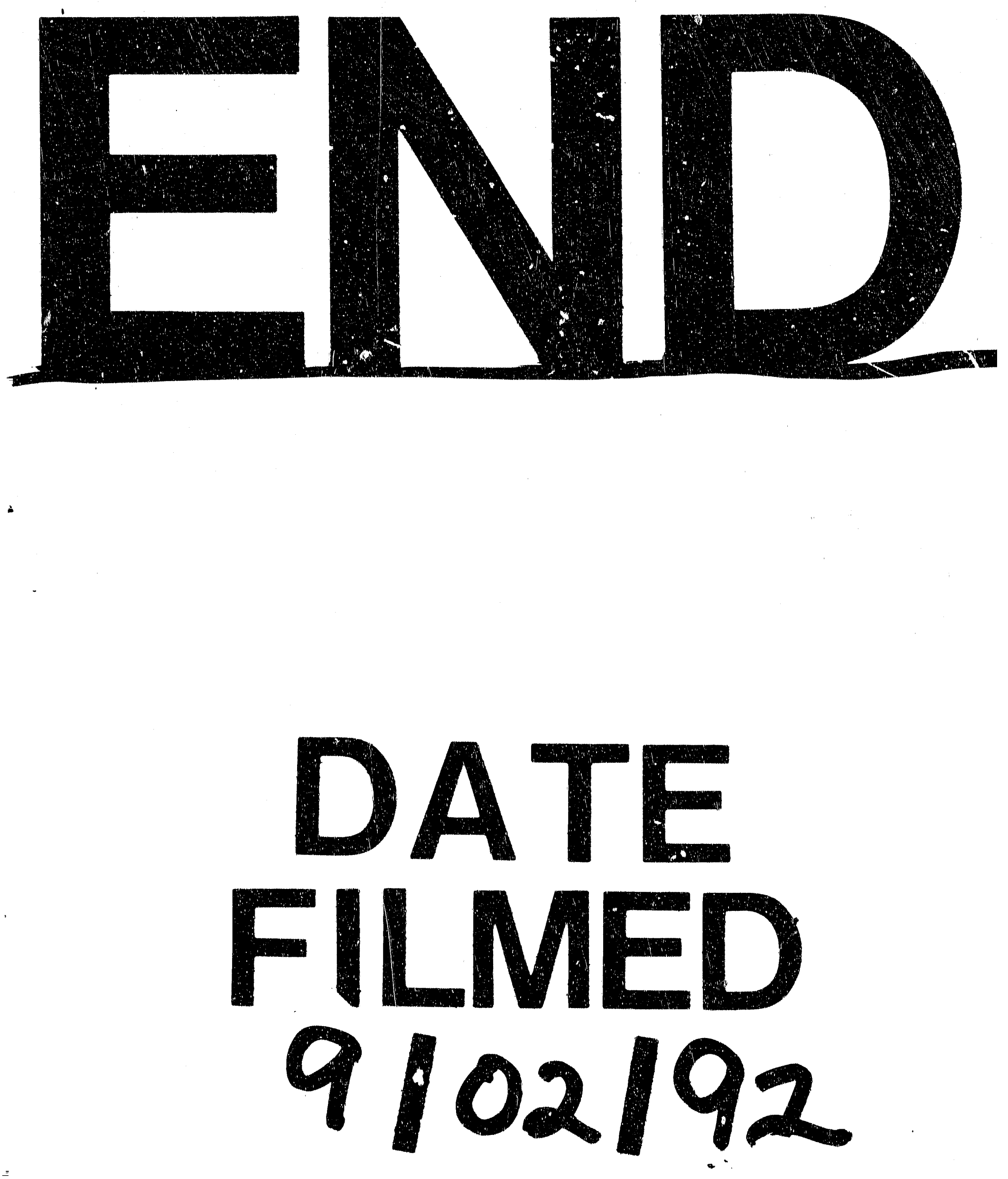

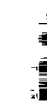


